\title{
De indianismo eCLesiástico y OtRos. CatOlicismo SOCIAL, DISCURSOS Y PRÁCTICAS ÉTNICAS EN MICHOACÁN (1940-1950)
}

\author{
Jesús Solís Cruz
}

Resumen: A finales de 1930 el gobierno mexicano inauguró en Michoacán una nueva etapa de la política indigenista tendiente a integrar a este sector a la sociedad nacional. La práctica institucional en que derivó significó también un novedoso intento por incorporar a losindígenas alaestructura corporativadel Estadoposrevolucionario. No obstante su pretensión hegemónica, esta propuesta encontró su contraparte en otra impulsada por la Iglesia católica. En Michoacán desdeprincipios del siglo $x x$, en el contexto de un renovado catolicismo social, seglares y prelados promovieron un apostolado indígena comprometido con susraíces culturales. Dediversosmodossecontinuó este indianismo eclesial encontrándose en tiempos recientes con la vertiente institucional y la disidente - pro-autonómica - La tesis que subyace en el trabajo es que el actual activismo indio michoacano es deudor, en este sentido, de dos proyectos político sociales: el de la Iglesia católica y el del Estado posrevolucionario.

Palabras clave: Estado, catolicismo social, etnicidad, Michoacán, nacionalismo.

Enviado a dictamen: 14 de junio de 2010

Aprobación: 18 de agosto de 2010

Revisiones: 1

Jesús Solís Cruz, Doctor en Antropología Social por El Colegio de Michoacán. Profesor del Centro de Estudios Superiores de México y Centroamérica de la Universidad de Ciencias y Artes de Chiapas. Temas de especialización: ciudadanía cultural, Estado, nacionalismo, antropología política. Correo electrónico: soliscruzlhotmail.com.
Abstract: At the end of 1930 the Mexican Government in Michoacán opened a new stage indigenist policy aimed at integrating this sector to the national society. The institutional practice that derived, also meant an innovative attempt to incorporate indigenous peoples to the corporate structure of the State post-revolutionary. However its hegemonic claim, this proposal found its counterpart in another driven by the Catholic Church. In Michoacán from early 20th century in the context of a renewed social Catholicism, lay and prelates promoted an indigenous apostolate committed to their cultural roots. In various ways continued this ecclesial indianismo found in recent times with the institutional side and the dissident (pro-autonomic). The thesis that underlies this work is the current michoacano Indian activism debtor in this regard, two social political projects: the Catholic Church and State postrevolutionary.

Keywords: State, social catholicism, ethnicity, Michoacán, nationalism.

\section{Introducción}

T asúltimas décadas han atestiguado la emergencia de numerosos movimientos indígenas en diversas partes del mundo. Estudios recientes que se ocupan de los mismos han descrito detalladamente los marcos y estrategias políticas en que se desarrollan, 
así como los discursos y las reivindicaciones de derechos culturales que formulan frente al Estado. Otros análisis los han identificado como respuestas contrahegemónicas al sistema capitalista global (Castells, 1999). Algunos más indagan el uso discursivo de categorías como cultura e identidad étnica, y el acomodo que estos movimientos tienen en proyectos de corte neoliberal que supuestamente debieran serles contrapuestos (Kirsch, 2007). En esta última línea quien presenta la posición más radical, pero también una de las más firmemente argumentada, es Adam Kuper (2003). Este autor sostiene que si bien las demandas de estos grupos movilizados pueden ser legítimas, las ideas detrás de las mismas -alentadas por el Banco Mundial, las Naciones Unidas, agencias internacionales de desarrollo y organismos no gubernamentales - son dudosas y los resultados, en potencia, políticamente peligrosos.

En México los estudios sobre el movimiento indígena han privilegiado las rutas analíticas que focalizan las oportunidades y las estrategias políticas, la discursividad y la fuerza moral de los reclamos de derechos culturales (ver Harvey, 2000; Villoro, 2002). También se han producido análisis que ubican a estos movimientos en marcos de relaciones sociales y de poderes regionales más amplios (Vázquez, 1992a; Zárate, 2001). Unos y otros asumen en general que la politización de la identidad étnica —indianidad o etnicidad— ha emergido tutelada por las acciones institucionales de gobierno, incluso las expresiones críticas y disidentes. El Estado nacional mexicano, según estos trabajos, es un actor central en la construcción de indianidad, bien como fuente o como referente negativo de símbolos y significados identitarios.

Un tanto a distancia de estas perspectivas se encuentran los análisis que, sin obviar la participación gubernamental, atienden la incidencia que otros agentes, como los religiosos católicos, han tenido en el "reavivamiento" étnico en México. Un estudio representativo del anterior tipo es el de Víctor Gabriel
Muro (1994), al que de manera reciente se han sumado los realizados por José Luis Escalona (2001), Jesús Morales (2005) y Marco Estrada (2007). Desde distintos abordajes teóricos y metodológicos estos autores han mostrado cómo en entidades como Chiapas y Oaxaca la etnicidad contemporánea emergió fundamentalmente en contextos y a partir de iniciativas religiosas.

El presente artículo se plantea analizar el papel del trabajo evangelizador, realizado por agentes católicos, en la formación de una conciencia étnica en Michoacán. Sin dejar de lado la política oficial indigenista, me propongo examinar la introducción del proyecto social promovido por la Iglesia católica en el estado de Michoacán que tuvo, entre otras, la finalidad de transformar prácticas y símbolos colectivos compartidos, en rasgos de identidad y cultura étnica entonces nombrada "Tarasca". Analizo la vertiente magisterial y el carácter étnico de esta política católica, en un período que comprende fundamental aunque no exclusivamente las décadas 1940 y 1950.

De manera particular me interesa referir algunos hallazgos documentales y etnográficos que dan cuenta del proceso iniciado por un sector de la Iglesia, que llevó a readecuar la concepción sobre el "ser" purhépecha.

La tesis que busco desarrollar en este trabajo es que la iniciativa social católica venida desde finales del siglo XIX en México, en su orientación magisterial y asistencialista de los "naturales", sentó las bases de lo que más tarde se habría de conceptualizar como diferencia cultural y potencializar como recurso político. En el caso michoacano la noción de sujetos indios o la "purhépechidad" vigente deriva en buena medida de la labor pastoral que un sector de sacerdotes desde la década de 1940, apoyados por autoridades eclesiales, impulsó a propósito del reconocimiento de sí mismos como indios. Cabe apuntar que en su etapa inicial el apostolado eclesial indio se situó a contracorriente de la acción indigenista institucional; hubo, no obstante, de confluir con la misma política gubernamental y con las expresiones críticas surgidas de ella. 
Un apunte más: la tesis que aquí sostengo puede caracterizarse como preliminar, para afianzarla se requerirá profundizar en la etnografía histórica y documental. Pese a ello no quiero dejar de proponer la tarea de evaluar, en los estudios sobre etnicidad en Michoacán, la incidencia del activismo social católico en la formación de significados y prácticas étnicas.

\section{Otras anotaciones: de contexto ideológico y abordaje teórico}

A pesar de los reiterados intentos que desde los gobiernos decimonónicos se han hecho para desplazar los apegos regionales y comunitarios, con el objeto de generar sentimientos y formas de adscripción política ligadas a la comunidad nacional, aquellos han persistido.

La histórica ausencia de un Estado fuerte, proveedor de un igualmente enérgico sentimiento nacionalista, permitió que instituciones locales como las formas de gobierno indígena, las cofradías y demás organizaciones de tipo parroquial, continuaran definiendo los sentidos culturales y sociales hasta bien entrado el siglo XX. La Iglesia católica desempeñó una importante posición rectoral en aquella fase definiendo si no sentidos de adscripción tan amplios sí los de tipo regional. Gonzalo Aguirre Beltrán, de hecho, sostenía que este parroquialismo conducía a un marcado etnocentrismo en detrimento, se entiende, de la identidad nacional. ${ }^{1}$

Los gobiernos posrevolucionarios en México, enfrentados con esta realidad y apurados por la creación de una nación a la altura de las más avanzadas, crearon un ideario nacionalista que bajo la lógica del poder y el control político buscó subordinar e institucionalizar las antiguas formas de asociación, fuentes de identidad. Para la fase posrevolucionaria, esta idea generó prácticas que mediante la acción institucional buscaron crear al México mestizo. Estas prácticas institucionales, intentos además de legitimación política que han buscado crear una identidad colectiva nacional, se resumen en la producción de un prototipo nacional: "el mexicano". Racialmente mejorado y sintetizado, espiritualmente proclive a las luces de la modernidad, propietario de sí y de sus bienes, "el mexicano" vino a establecerse como rasgo de distinción dentro de la pluralidad cultural del país. En contraste, se utilizó la imagen del indio o la vida rural sumida en la ignorancia, el atraso y la podredumbre moral.

Sin embargo, la fundación del "ser nacional" no se remitía exclusivamente a un ideal identitario, sino que se enmarcaba en la primordial necesidad de construcción de la sociedad y el Estado moderno bajo un gobierno fuerte, capaz de controlar formaciones de poder que funcionaban como pequeños "estados dentro del Estado” (Lameiras, 1999: 22). Un asunto, pues, de legitimación política y centralización del gobierno ante la diversidad.

Así, la política institucional que se planteó la uniformidad y la integración de la sociedad nacional estuvo guiada no solo por principios de férreo control estatal sino también por otros de afirmación de las diferencias raciales, legitimadas a la vez por preceptos de civilidad y modernidad. Todo esto decantó en una tarea de Estado que de un lado intentó la recreación cultural y de otro la transformación social de los pueblos originarios.

Oficialmente en 1936, durante la presidencia del general Lázaro Cárdenas, se fundó el Departamento de Asuntos Indígenas; a partir de entonces dio inicio la acción indigenista institucional.

En Paracho, Michoacán, por ejemplo, en ese mismo año 36 se instaló el internado indígena. Tres años más tarde se establecieron, en la misma cabecera municipal, las oficinas del Proyecto Tarasco. Uno de los propósitos fundamentales de estos proyectos era modernizar a las localidades indígenas mediante la escolarización. Pero también devinieron en espacios de educación política. Fue el caso del ya mencionado internado, "cuna cardenista" de muchos líderes indígenas purhépecha (Vázquez, 1992b). 
Consuficienciaydemejormanera se hadocumentado y discutido el devenir de la política oficial en materia indígena, ahora sólo quiero repetir que surgió articulada al discurso nacionalista modernizador de orientación asimilacionista e integracionista, según la fase, que tuvo indistintamente propósitos corporativistas. No es desproporcionado afirmar que se planteó, también, como un contrapeso al predominio que la Iglesia tenía en la ordenación y regulación de la vida pública en los niveles comunitarios.

En este punto importa destacar cómo después de la fase armada en el conflicto Iglesia-Estado (1920-1930), la pugna continúo desarrollándose en dos planos: la constitución de organizaciones y la formación de sujetos (Plancarte, 1993: 29-34). Y aunque a esto volveré en el siguiente apartado cuando aborde la política social eclesiástica y el conflicto religioso, sirve la anotación para señalar que la disputa no se resume en el simple hecho de buscar el control de "masas", tuvo -y continúa teniendo - como principal móvil la definición de competencias de gobierno y de legitimidad a la hora de crear categorizaciones colectivas. En sentido amplio se trataba en aquel momento - y todavía trata- de una disputa relacionada con el orden moral y político. La pugna entre la Iglesia católica y el Estado mexicano posrevolucionario debe entenderse así como una lucha de poder en la que se estaba dirimiendo la función rectoral entre fuerzas orgánicas cohesionadoras de la sustancia social.

En esa línea, argumento aquí que como "asociación de dominio de tipo institucional" (Weber, 1981, 2006) el Estado, en este caso el mexicano, se constituye a partir de la negociación y confrontación con otras formaciones políticas y modos de representación y mediación en la sociedad (Becker, 1987; Joseph y Nugent, 2002; Guerra, 2008).

Es desde esta perspectiva que destaco en este artículo otras formas de representación social, de producción de sujetos colectivos distanciada o contrahecha a la versión oficial. Para la consideración de esta dimensión social ha sido ilustrativo el trabajo de Jean y John Comaroff donde examinan, en el contexto colonial africano, la labor realizada por misioneros religiosos, a la par de la de algunos funcionarios coloniales, que derivó en trascendentales transformaciones sociales, políticas y económicas en aquella región. Aún más, destacan las variadas formas en las que la "cultura" sembrada por los religiosos prendió raíces en el terreno social, a tal grado que fue "silenciosa y perfectamente absorbida en una reinventada —o, mejor, deificada - 'tradición' étnica” (1991: 7-12, énfasis y traducción propios). Un proceso similar al descrito en los siguientes apartados.

\section{La política social católica y el conflicto religioso}

A finales del siglo XIX, en el contexto del renovado impulso del movimiento socialista en Europa, el Papa León XIII puso en marcha una novedosa estrategia de acercamiento a la sociedad en la que se planteaba el interés en los problemas sociales. Esta preocupación plasmada y publicada en 1891 en la Encíclica Rerum Novarum marcaría el paso de un tipo de catolicismo inactivo y apolítico a otro de carácter moralizador, activista y comprometido con el ofrecimiento de soluciones a los problemas sociales de su tiempo (Ceballos, 1983).

En México, la influencia de la Encíclica comenzó a percibirse con mayor fuerza hacia principios del siglo XX. Después de un proceso de asimilación doctrinaria se llevó a cabo el primer congreso católico en Puebla en el año 1903, en el que el asunto central fue el sindicalismo católico. Le siguió el celebrado en Morelia en 1904 sobre la asistencia económica y cultural de los grupos obreros, el alcoholismo, y por primera vez se abordó el tema de la promoción del indio. Los acuerdos más importantes en esa línea fueron: la fundación de escuelas elementales para indígenas en cada diócesis, reproduciendo la experiencia del colegio Vasco de Quiroga fundado en Erongarícuaro por el arzobispo de Michoacán 
Atenógenes Silva; la formación de abogados capaces de orientar a los pueblos indígenas, e igualmente acordaron efectuar campaña entre los indios con la finalidad de desterrar el alcoholismo (Díaz, 2003). Dos años más tarde fue celebrado otro congreso católico en Guadalajara, en donde el tema central fue la justicia social y las obligaciones de los patrones hacia sus trabajadores; bajo el mismo tenor hubo uno realizado en Oaxaca en 1909. También se efectuaron en este marco tres congresos agrícolas, dos en Tulancingo en los años 1904 y 1905, y uno en Zamora en 1906 (Meyer, 1973). Todas esas acciones marcarían el comienzo en México de la acción y pensamiento social católico o catolicismo social.

Al cobijo de la Rerum Novarum y con la aprobación y promoción de las autoridades eclesiásticas, se fomentaron grupos católicos de auxilio mutuo, cajas de ahorro, círculos de católicos obreros y sindicatos.

En Michoacán, la actividad social católica era particularmente activa, sobre todo en el impulso a la educación y la formación de asociaciones. Antes de que los gobiernos instauraran escuelas públicas en las pequeñas localidades, los curas lo habían hecho. Por ejemplo, en las parroquias de Coeneo, Tiríndaro y Zacapu, ubicadas en el bajío michoacano, desde principios del siglo XX se registró la creación de escuelas católicas. Aunque algunas tuvieron vidas muy breves, otras observaron a partir de la década del cuarenta del mismo siglo una mayor difusión (entrevista presbítero Efrén Cervantes, arquidiócesis de Morelia, mayo de 2006). Muchas de ellas, como la que existió en Tiríndaro, fueron sostenidas por hacendados. Como resultado de toda la actividad magisterial eclesiástica en el año 1905 se contaba con 135 escuelas católicas en la arquidiócesis de Morelia (Díaz, 2003: 131-134). ${ }^{2}$

En el plano meramente político, en el estado de Michoacán se estableció un centro regional del Partido Católico Nacional desde donde se promocionaban derechos de ciudadanía y se alertaba a sus seguidores de los peligros del socialismo, manifiesto en los movimientos revolucionarios que ocurrían por esos años en la entidad y en otras partes de la república (véase Ceballos, 1983).

En la etapa posrevolucionaria en México, estas iniciativas religiosas fueron confrontadas con las de los gobiernos nacionales y sus agentes. El Estado posrevolucionario, concebido como proveedor de valores y de ideas de la deseable sociedad mexicana, visto incluso como encarnación de la misma sociedad, no podía admitir la presencia de instituciones como la Iglesia encargándose de la labor de sociabilidad y transmisión de valores. En este contexto inició la confrontación política con la Iglesia hacia la segunda década del siglo XX que tuvo como resultado violento la "rebelión cristera".

Aunque la disputa tuvo desenlaces sangrientos en el ámbito popular, también transcurrió sobre temas que habían ocupado de antaño a seglares y prelados católicos: sindicalismo obrero, desarrollo y organización rural, libertades políticas y educación; este último hubo de situarse como la más importante arena de disputa.

Bajo dicho tenor el momento de mayor tirantez interinstitucional lo marcó el conocido como "Grito de Guadalajara” del presidente Plutarco Elías Calles en 1934, en el que expresaba que a la "Revolución" le pertenecían las conciencias de la juventud y de la niñez, y por tanto el gobierno nacional debía apoderárselas sacando al enemigo - la clerecía y los conservadores - del espacio donde las apropiaban: la educación (Plancarte, 1993: 32). Si bien se pueden recuperar elementos de mayor relevancia que proporcionan una perspectiva clara sobre la ofensiva gubernamental hacia la educación religiosa, me parece simbólicamente representativa la manera en que fueron nombradas las campañas educativas y de capacitación laboral que el gobierno efectuó en aquella etapa: "misiones culturales", una clara analogía al lenguaje teológico, donde el misticismo del que se hallaban impregnados los agentes misioneros civiles se encontraba en competencia sin duda al espíritu de sus pares religiosos. 
Por otro lado, la "rebelión cristera", manifiesta de manera irregular y sangrienta desde principios de 1920 en el occidente y bajío mexicano, había tenido para el momento del Grito de Guadalajara una tregua en junio de 1929. Esta revuelta en la que participaron rancheros tradicionalistas, indígenas purhépecha, tepehuanes y tarahumaras, guiada por principios defensivos de la fe y de los valores que otorgaban sentidos a la vida cotidiana de los alzados, fue una respuesta violenta que expuso la carencia de legitimidad del Estado posrevolucionario (Becker, 1987).

Aunque a escala institucional ocurrieron los conocidos como "arreglos de 1929", encaminados a lograr la convivencia pacífica y la continuidad de la labor de la Iglesia, durante 1930 siguieron registrándose brotes violentos. Para la siguiente década, en la etapa final del gobierno del general Lázaro Cárdenas y en el comienzo del de Manuel Ávila Camacho, hubo una atenuación del discurso anticlerical y un giro en materia social gubernamental que permitió un relativo acercamiento con la visión de la Iglesia (Plancarte, 1993: 63-115). Este es el transfondo de la renovada marcha que emprendieron los religiosos por instaurar un orden social cristiano y una justicia social con orientación eclesial.

\section{El catolicismo social y su vertiente indianista. La protonación purhépecha}

El trabajo evangelizador que la Iglesia católica emprendió para "reencauzar" la sociedad nacional en el período de posguerra, requirió del apoyo de asociaciones de tipo laico. Acción Católica, organización de ese tipo, fundada en 1929, se convirtió en un instrumento importante para ese fin. Devenida en vocera de los intereses de las autoridades religiosas, Acción Católica funcionó también como una red nacional que transmitía las directrices de los prelados a las asociaciones locales. En contrapunto sin duda con el proyecto de legitimación política del Estado, la Acción Católica se sectorizó - Acción Católica de la Juventud Mexicana, Acción Católica Femenina, etcétera- e intentó con ello asegurar la presencia institucional de la Iglesia en las más diversas esferas sociales, incluso en ambientes marcadamente anticlericales.

Aunque en el tema de la revaloración étnica no es posible conocer el grado de incidencia de Acción Católica, no hay duda de que apoyados en esta y sus ramas un grupo de sacerdotes michoacanos implementó hacia la década de 1940 un trabajo pastoral comprometido con la instrucción y revaloración de los sujetos indios. En tiempos recientes los religiosos han intelectualizado aquella labor y la han identificado como deudora del legado espiritual y humanista del primer obispo de Michoacán Don Vasco de Quiroga. A continuación me ocuparé de ella, debo decir antes que se inscribió en un ambiente en el que los valores laicos arraigaban cada vez más en la sociedad mexicana. De igual forma, en este punto, quiero adelantar la siguiente consideración: la revaloración cultural y la política étnica manifiestas en las agrupaciones y movilizaciones sociales regionales de finales de la década del ochenta y de principios del noventa del siglo XX tienen como antecedente directo las acciones que los clérigos efectuaron hacia la década del cuarenta en Michoacán.

En términos geográfico espaciales resulta evidente esta relación. Como antes he apuntado, se requiere una mayor profundidad documental y etnográfica, no obstante, los pocos datos con que cuento remiten a una coincidencia entre la geografía políticamente activa en la que se ha desarrollado de manera importante y reciente el reclamo de reconocimiento de derechos étnicos, y el espacio en que efectuaron su labor misionera y social los religiosos: Nahuatzen, Pichátaro, Santa Fe de la Laguna, Charapan, Ihuatzio, San Juan Nuevo, Cherán, Cucuchucho, San Jerónimo, Cuanajo, Santa Ana, San Andrés, Pamatacuaro, Pátzcuaro, Paracho y Tiríndaro. ${ }^{3}$ 


\section{Veamos el proyecto eclesiástico indianista}

Algunos sacerdotes con ascendencia indígena, pertenecientes a las diócesis de Morelia y Zamora, emprendieron una importante labor de promoción y rescate de "la cultura y costumbre tarascos" a través de la escolarización y enseñanza católica en la década de los cuarenta. ${ }^{4}$

La creación de "escuelas de primeras letras" fue uno de los primeros pasos que dieron estos religiosos en Michoacán, para reinsertarse en las localidades indígenas de las que eran originarios o conocían por compartir origen étnico.

Hoy reconocen como impulsor de aquella iniciativa al padre Adolfo Soriano, originario de la comunidad indígena de Pichátaro. Fue, se dice, incansable promotor de catequistas, de la formación de maestras para enseñanza en escuelas particulares y de grupos corales. La integración del grupo de catequistas indígenas, apoyo importante del cura Soriano, se debió a las misiones que las madres guadalupanas realizaron en la región del lago de Pátzcuaro. El padre Soriano, luego de un período de preparación en la ciudad de Querétaro, se llevó a las catequistas indígenas a Pátzcuaro. Ahí las consagró y nombró, en diciembre de 1939, María Inmaculada de la Salud.

El cura llegó a integrar un grupo de cuarenta catequistas y con ellas atendió doce escuelas en las que enseñaron, desde 1940, además de las primeras letras el catecismo. Como resultado de la enseñanza en aquellas escuelas contabilizaron tiempo después once sacerdotes, dos religiosas, varios maestros y "muchos buenos padres de familia". Con su equipo pastoral el padre Soriano logró instalar además un internado en Zacuapio, península del lago de Pátzcuaro, además de una casa albergue en Quiroga que recibía niños de ambos sexos que deseaban continuar sus estudios, y fundaron un periódico con propósitos catequísticos llamado La Vozde Tata Vasco. Como parte de esa misma propuesta, aunque no es posible saber si de manera coordinada, se registró hacia esos mismos años la decisión del cura Julio Avilés de instalar en Morelia un internado que recibiera a jóvenes purhépecha que llegaban a aquella ciudad a realizar sus estudios superiores. ${ }^{5}$

No obstante que es un tanto difícil seguir de manera puntual el desarrollo del proyecto, se tienen noticias de que para finales de 1940 en Michoacán había integrada lo que se denominaba "Comisión Diocesana ProTarascos". Sus miembros en junio de 1948 sostuvieron una reunión extraordinaria en Pátzcuaro — cuna del indigenismo oficial integracionista - a la que asistieron además del abad Rafael Méndez, el canónigo Efrén Urincho y el presbítero Juan Navarro - asistente general de Acción Católica-, además de una veintena de curas de igual número de pueblos, entre los que se contaron: Santa Fe de la Laguna, Tzinzuntzan, San Jerónimo Purenchecuaro, Cherán, Paracho, Coeneo, Tiríndaro, Tarecuato y Chilchota. ${ }^{6}$

En las conclusiones derivadas de aquella reunión se plantearon sostener el contacto con el "Consejo de Asistentes" de la Acción Católica, informándole de actividades y movimientos. Se propusieron, también, seguir las orientaciones de Acción Católica. Signaron el compromiso de colaborar en el periódico La Vozde Tata Vasco y enviar si las circunstancias les era favorable a un joven para instruirse en asuntos agrícolas a la dirección que Acción Católica tenía en ese ramo. De manera aún más precisa señalaron el propósito de trabajar en el fomento de "la cultura y costumbres de los tarascos". Misma que concebían como contenida y definida por la lengua, pues agregaron: "sin excluir el castellano, pero sí despertando interés y estimación por su lengua nativa". Señalaron en ese sentido la loable y urgente labor de fundar una "Academia de la Lengua Tarasca", que debía quedar a cargo de iniciativas privadas. Pero sobre todo se fijaron como meta trabajar para ayudar "el instinto y formación de naturales" ?

La continuidad de este proceso en términos generales es difícil de documentar, no obstante, con base en la correspondencia de uno de los curas participantes 
en el mismo, se puede seguir el desarrollo del proyecto. Se trata de José Padilla, párroco de Tiríndaro, pueblo localizado en el Valle de Zacapu.

Medio año después de que se dictaran las mencionadas conclusiones, en diciembre de 1948 el padre Padilla recibió un citatorio para la novena reunión de la Comisión Pro-Tarascos. A decir por los puntos señalados a tratar, una de las preocupaciones latentes era la definición de la formación de los jóvenes tarascos en el concierto de sus "tradiciones"; se preguntaban en primer término: "ien qué consiste en concreto la formación de nuestros jóvenes tarascos, según sus tradiciones naturales?". En esta misma ocasión también reclamaron artículos para el periódico Tata Vasco, datos para una conferencia Pro-Tarascos en el seminario de Morelia, y solicitaron que fueran presentadas por escrito las correcciones de los estatutos que regirían a aquella Comisión. ${ }^{8}$

Existen vacíos documentales o fragmentación en la información sobre el tema, debido entre otras razones a que durante un lapso considerable de tiempo los miembros de la Comisión no se reunieron.

Sin embargo, apoyándome en los documentos localizados, me permito asegurar que los trabajos por el apostolado indígena continuaron en el ámbito diocesano. De nueva cuenta, la correspondencia del párroco de Tiríndaro es de suma utilidad en este sentido.

En 1955 comunicaban desde la secretaría del arzobispado de Morelia al padre José Padilla que había en aquella ciudad un "Colegio Pro-Tarascas", donde se formaba a jóvenes de lengua tarasca instruyéndoles en religión y demás "conocimientos útiles" por un pago mensual de 40 pesos. Se hacía saber de la necesaria asistencia de alumnas para conseguir el sostenimiento del colegio. Al mismo tiempo, se interrogaba al cura sobre la utilidad de la obra y la disposición de algunas jóvenes para acudir. ${ }^{9}$

En su respuesta el cura Padilla dijo que aquella le parecía una obra de suma utilidad para otros pueblos que se hallaban más "aislados material y moralmente" y que se habían empeñado en conservar la lengua y "costumbres tarascos". En particular para Tiríndaro, dijo, el proyecto resultaba de poco provecho pues algunas jóvenes juzgaban "quizá erróneamente haber progresado al abandonar dichas costumbres" y habían perdido el interés de hablar el tarasco creando un complejo de inferioridad hacia "las tradicionalistas". Debido a lo mismo, consideraba poco probable que alguna fuera a estudiar a aquel colegio, y señaló que las que hubiesen podido hacerlo se encontraban seis becadas en la Técnica Industrial de Morelia, un número igual en la Escuela Normal de Tiripetío, dos más que no tenían los medios para pagarse los estudios en una escuela de Jalisco, y las que podían pagar estaban desde hacía algunos años con las religiosas Josefinas y Trinitarias en Pátzcuaro y en Morelia..$^{10}$

La contestación del cura resulta interesante por ilustrativa del gradual avance y aceptación de la educación laica, del proyecto integracionista y la política indigenista gubernamental en aquellos pueblos, de aquellos años. Era el momento de mayor auge del indigenismo de integración.

Quiero con todo esto señalar que el proyecto indianista católico de las décadas 1940 y 1950 en Michoacán comenzó a aminorar sus acciones y a ser desplazado por otros, con pretensiones más "revolucionarias". Refiero al gubernamental y al eclesiástico posteriores a la década de 1960. El primero comenzó hacia este período a alentar una perspectiva crítica al paradigma integracionista que lo había regido, e incorporó la consideración de la pluralidad cultural, de igual modo integró demandas y discursos de los actores indios, formados en la disidencia política y herederos muchos de ellos del mensaje pastoral católico de revaloración india. El segundo proyecto —el eclesiástico-implementó una pastoral social más activa y comprometida con las soluciones a los problemas sociales de los pobres, que en el caso mexicano y centroamericano distintivamente resultan ser los indígenas. 
El derrotero que en México siguió la política indianista tanto gubernamental como eclesiástica, después de 1960, es menos lineal. Ocurrieron confluencias y colaboraciones entre instituciones gubernamentales y eclesiásticas, así como distanciamientos muy marcados. El caso del Congreso Indígena celebrado en Chiapas en 1974 es paradigmático en ese sentido, y lo es todavía más por las derivaciones disidentes - a la institución religiosa y a la estatal - que propició aliento a la vez de novedosos procesos políticos (véase Morales, 1995).

La pastoral social católica dirigida a los indígenas que se implementó en México después de la década de 1960 opacó las iniciativas que le habían antecedido, como la michoacana de las décadas de 1940 y 1950. El destacado protagonismo de la pastoral católica, en su nueva vertiente indianista, en parte se debió a la beligerancia de su discurso, a la promoción de la defensa de derechos sociales y a la cercanía ideológica de sus impulsores con los movimientos sociales de izquierda, preocupados por el destino de las empobrecidas masas. Quizá debido a esto los trabajos académicos que analizan la etnicidad y la imbricación con proyectos religiosos institucionales también enfaticen lo acontecido después de la década de 1960, en detrimento del análisis de iniciativas como la que he venido describiendo, ocurrida en Michoacán. ${ }^{11}$

\section{El continente indiano contemporáneo}

El orgullo étnico en Michoacán, en su expresión masiva, no arraigó en el movimiento social que en el campo se desarrolló hacia la década de 1970. Sobre todo parece alejado de la protesta pública catalogada como independiente a los gobiernos nacionales y a todo medio institucional. Eso es así por ejemplo con el caso de la Unión de Comuneros Emiliano Zapata (UCEZ), emblemática organización social de tipo rural y referente histórico obligado de los actuales movimientos sociales disidentes michoacanos. Constituida formalmente en el año 1979, en el programa de lucha y discursivo de
UCEZ no figuró la categoría de indígena. En cambio se sobrevaloró la de campesino. Fue en torno a esta categoría y a su programa de movilización y demandas encaminadas al activismo político y a la recuperación de tierras que la unión logró aglutinar más de ochenta comunidades y ejidos michoacanos (Zárate, 1999a).

Por el contrario, la difusión constante y masiva de los sentimientos étnicos, utilizados incluso como instrumentos para la movilización social, llegó por mediación de asociaciones y formas de representación social caracterizadas por algunos académicos como "oficiales": la Asociación Nacional de Profesionistas Bilingües, A. C. (ANPIBAC) y los Consejos Supremos (Vázquez, 1992a).

Haciala década delos años ochenta es posible percibir el repunte del discurso étnico entre organizaciones autoidentificadas como indias. Y fue en este período que comenzaron a emerger organizaciones que reclamaron además de la adscripción de indígena la identificación como independientes al gobierno. Incluso este tipo de organizaciones amplió sus vínculos, y fue así que en marzo de 1981 se realizó el Segundo Encuentro de Organizaciones Indígenas Independientes de México, Centroamérica y el Caribe en Cheranástico, y en 1983 se constituyó la organización Camino del Pueblo, Xanaru Ireteri.

Pero aun cuando estas organizaciones acudían a la autoadscripción indígena, en sus programas de acción predominaban demandas de carácter agrario y asistencialista. Les ocupaban sobre todo la resolución de los problemas agrarios inter e intra comunitarios, al igual que la reactivación y modernización de la producción del campo. La condición cultural, cuando aparecía, estaba abrigada por un discurso proletario. Por ejemplo, entre las propuestas políticas de Xanaru Ireteri se planteaban el rescate y proletarización de la cultura purhépecha (Máximo, 2003).

Todavía para aquel momento la representatividad y la claridad del programa en los reclamos culturales eran limitadas. 
En 1983 inició lo que ha sido considerado la propuesta étnica más acabada de las organizaciones de corte cultural en Michoacán: la fiesta del Año Nuevo Purhépecha (Zarate, 1999).

En 1991 se realizó el Primer Encuentro de Organizaciones Indígenas de Michoacán en Cherán, como resultado del mismo se constituyó el Frente Independiente de Comunidades Indígenas de Michoacán (FICIM). En diciembre del mismo año el Frente emitió el Decreto de la Nación Purhépecha que fue ratificado en el Segundo Encuentro de Comunidades Indígenas de Michoacán celebrado en Tarecuato en 1994.

En 1993 el FICIM se fragmentó en dos corrientes: "radicales y tranquilos"; ante la continua división y surgimiento de nuevas organizaciones se integró la Organización Nación Purhépecha promovida por ANPIBAC y otros profesionistas purhépecha (Zárate, 1999). Es justo aquí donde se localiza el origen inmediato del movimiento indígena michoacano contemporáneo; por otro lado, los orígenes más remotos, como he venido señalando, pueden rastrearse en la pastoral católica indígena.

Una especie de síntesis del proyecto religioso y gubernamental de revaloración cultural, desde mi perspectiva, es la fiesta del Año Nuevo Purhépecha, en tanto que entre sus más destacados promotores se cuentan sacerdotes, profesionistas e intelectuales (ver al respecto Zárate, 1999); los últimos formados en instituciones y programas oficiales de orientación indigenista.

Antes de concluir este apartado me parece pertinente hacer una acotación de tipo metodológico. La reconstrucción del proceso de reindianización y su análisis resultan incompletos si no se examinan en el marco de la historia social y política regional. Aunque tal empresa sería tema para otro trabajo, quiero por lo menos aquí enunciar tres hechos sociales generales trascendentes en el revival étnico michoacano: el primero tiene que ver con la emergencia de una economía asentada en la explotación forestal que propició un discurso de autentificación étnica para acceder a la tierra y a los bosques, ${ }^{12}$ el segundo con los cambios en la cultura política regional, concretamente con el neocardenismo de finales de la década de 1980 que decantó en la conformación del Partido de la Revolución Democrática y en una complejización de la arena política regida por reglas y valores de la democracia electoral; y el tercer hecho, íntimamente relacionado con la política eclesial indianista que he referido aquí, se asocia con la formación de una amplia capa de profesionales indígenas gestores de una conciencia política cifrada en la diferencia cultural.

\section{Conclusiones}

De vuelta al catolicismo y a su línea pastoral orientada hacia la revaloración cultural creo importante para concluir hacer los siguientes señalamientos.

La labor magisterial y la pastoral proindianista, que un sector de sacerdotes inició en la década de 1940 y continuó hasta al menos finales de 1950, parecen no haber incidido en el actual reavivamiento del orgullo étnico michoacano. Tanto en el discurso como en los temas que las organizaciones indígenas manejan, la iniciativa religiosa parece estar ausente. Incluso esta ausencia se presenta en los análisis y discursos académicos recientes que tratan el movimiento indígena michoacano. La ausencia en este último sentido se explica por la también carencia de una historia social que muestre la transformación de las sociedades indígenas. Se requieren análisis que como he señalado no sean únicamente enunciativos o descriptivos del reciente indianismo devenido en movimiento social en Michoacán, sino además críticos y explicativos de las condiciones sociales, los proyectos ideológicos y los procesos políticos dominantes en que ha venido ocurriendo. En este trabajo, con base en los escasos hallazgos etnográficos y documentales presentados, he buscado llamar la atención sobre la necesidad de realizar investigaciones en esta última línea. 
Así, bajo una mirada atenta se puede localizar que la propuesta eclesial de la década de 1940 —donde no hubo una consecuente implementación, no tanto en sus aspectos digamos formales, como fundación de escuelas o impartición de doctrina religiosa en alguna de las existentes, influyendo en los maestros- se tradujo en una magnifica promoción del rescate de las fiestas religiosas y de las "santas tradiciones", arrinconadas otrora por el ambiente anticlerical..$^{13}$

A partir de lo anterior sobrevino un reavivamiento de sentimientos colectivos con arraigos comunitarios muy fuertes. Resurgieron formas organizativas y representaciones de tipo civil que se entrelazaron con las religiosas y se reactivaron usos cultuales e implementaron actividades culturales que tuvieron como eje las festividades de los santos.

Todo este proceso ha dado origen a una revitalización de sentido de comunalidad y reificación de nativismo en diversas localidades michoacanas. Es interesante notar que esos relocalizados sentimientos étnicos y renovados usos cultuales y culturales forman parte hoy de las escenificaciones del "ser" purhépecha.

Es en este sentido que me parece que la iniciativa católica de los años 40 y 50 resulta importante; no solo se adelantó a la crítica que en las décadas de 1960 y 1970 se lanzaría desde la academia antropológica a la política indigenista impulsada por el Estado nacional, sino que también se situó como relevante en tanto proporcionó nuevos referentes políticos y sociales.

Aun en tiempos recientes se pueden localizar modestos esfuerzos que han contribuido al fortalecimiento del orgullo étnico en Michoacán. En el valle de Zacapu, por ejemplo, encontramos la labor que entre las décadas de 1960 y 1980 realizó Agustín García Alcaraz, cura y antropólogo, quien se preocupó por el rescate de símbolos y por la vigorización del "ser" purhépecha como sujeto político. Personaje central, además, en la fundación de la fiesta del Año Nuevo Purhépecha. Tal es el caso también del actual párroco de Nahuatzen, Francisco Martínez, quien desde hace varias décadas ha puesto a disposición de los pueblos de la Meseta sus conocimientos en hidráulica e hidrología al tiempo que ha contribuido a reavivar sentidos de adscripción comunal entre los purhépecha.

Por último señalar que aunque aquí he estado interesado en analizar el proyecto y la influencia que el catolicismo social y un sector de religiosos tuvo sobre la redefinición de la indianidad en Michoacán, no quiero dejar de mencionar que en tiempos recientes han sido importantes también las redes de relaciones que los miembros de organizaciones de tipo étnico han establecido fuera de sus marcos regionales que los han, por un lado, fortalecido en sus reclamos culturales y, por otro, ayudado a ampliar sus referentes discursivos. Pienso concretamente en vínculos con organismos no gubernamentales internacionales orientados a la defensa de derechos ambientales y humanos.

\section{Notas}

${ }^{1}$ Para una reflexión amplia en torno a la producción de identidades colectivas relacionada con la religión y sobre el proyecto académico y social de Aguirre Beltrán véase el trabajo de Guillermo de la Peña (2004).

${ }^{2}$ En 1863 fue elevada a arquidiócesis Morelia teniendo como diócesis sufragáneas: León, Querétaro y Zamora (consúltese al respecto Díaz, 2003: 103-106).

${ }^{3}$ Sobre el origen de los sacerdotes y el espacio en que realizaron labor catequística véase: Comisión de Historia del 450 Aniversario de la Diócesis de Morelia, Arzobispado de Morelia, 1986, p. 299. Para formarse una idea de la coincidencia entre la geografía donde ocurrió la labor de los religiosos que revaloró la cultura purhépecha, y la que actualmente se distingue por la existencia de reivindicaciones de derechos étnicos, el lector interesado puede remitirse a la propuesta de Ley sobre Derechos de los Pueblos originarios del estado de Michoacán y a la presentación de la misma hecha por Luis Ramírez (2002), consúltese además mapa anexo. 
${ }^{4}$ Es bastante probable que estos sacerdotes hayan sido educados como todos los de origen mexicano formados entre 1935 y 1950 en el Seminario de Santa María en Montezuma, Nuevo México, debido a la vigencia y aplicación de los preceptos legales anticlericales. Los maestros de este seminario eran jesuitas comprometidos con el catolicismo social, ello explicaría la sensibilidad de los sacerdotes purhépecha hacia la política social católica y el énfasis en la educación. Información obtenida en entrevista con el presbítero Efrén Cervantes, Arquidiócesis de Morelia, Morelia, mayo de 2006.

${ }^{5} \mathrm{La}$ información anterior proviene fundamentalmente del libro que con motivo del 450 aniversario del obispado de Michoacán se elaboró: Comisión de Historia del 450 Aniversario de la Diócesis de Morelia, Arzobispado de Morelia, 1986. Los datos referidos pueden consultarse en pp. 299-300.

6 "Conclusiones sesión Pro-Tarascos", una foja, Carpeta Mecanoscrito Padilla 4, Documento Digitalizado, proveniente del Archivo de Notarías de la Parroquia de Tiríndaro —en adelante ANPT-versión digital—. La clasificación y digitalización de los documentos estuvo a cargo del autor y del Ing. Hermilo Alonzo Téllez, y se compilaron con el título de Archivo de Notarías de la Parroquia de Tiríndaro. Copias digitales de este corpus documental se encuentran en la Biblioteca Pública de Tiríndaro. De forma deliberada he nombrado los anteriores pueblos para hacer notar la presencia de estos curas en las cuatro regiones que el actual movimiento étnico michoacano considera conforman la Nación Purhépecha, consúltese Luis Ramírez (2002).

7 "Conclusiones sesión Pro-Tarascos", una foja, Carpeta Mecanoscrito Padilla 4 en ANPT-versión digital.

8 "Reunión Pro-Tarascos", una foja, Carpeta Mecanoscrito Padilla 4 en ANPT-versión digital.

9 "Colegio Pro-Tarascas", una foja, Carpeta Mecanoscrito Padilla 4 en ANPT-versión digital.

10 "Respuesta Pro-Tarascas", una foja, Carpeta Mecanoscrito Padilla 4 en ANPT-versión digital.
${ }^{11}$ Después del alzamiento zapatista en Chiapas este tipo de trabajos fue común. Existen, no obstante, otros muy valiosos que exploran la pastoral católica y su relación con los pueblos indígenas de México desde una perspectiva crítica e histórica más profunda. Para una visión histórica amplia sobre la participación de la Iglesia católica en la vida social de México véase el trabajo ya citado de Roberto Plancarte (1993). Sobre el papel de la Iglesia católica en los movimientos populares y reivindicativos posteriores a la década de 1960 ver del mismo trabajo los capítulos V al VIII. En el mismo sentido véanse los trabajos ya referidos de Víctor Gabriel Muro (1994), José Luis Escalona (2001), Jesús Morales Bermúdez (2005), y Marco Estrada Saavedra (2007). En Michoacán se siguen extrañando análisis de este tipo.

${ }^{12}$ Un interesante análisis en esta línea puede encontrarse en Luis Vázquez León (1992b).

13 Por ejemplo, en el pueblo de Tiríndaro, perteneciente al municipio de Zacapu, hacia 1950 el cura acompañado por socios de la Unión Católica Femenina de México, la Juventud Católica Femenina de México y la Unión Católica de la Juventud Mexicana, reanimó las fiestas religiosas locales y motivó a los feligreses a rescatar danzas y demás ceremonias que las acompañaban.

\section{Bibliografía}

Becker, Marjorie (1987), "Black and White and Color: Cardenismo and the Search for a Campesino Ideology", en Comparative Studies in Society and History, vol. 29, núm. 3, (Jul., 1987), Cambridge: Cambridge University Press, pp. 453-465, download of www. jstor.org.

Castells, Manuel (1999), La era de la información. Economía, sociedad y cultura. El poder de la identidad, vol. II, México: Siglo Veintiuno editores.

Ceballos Ramírez, Manuel (1983), "La encíclica Rerum Novarum y los trabajadores católicos en la ciudad de 
México (1891-1913)", en Historia Mexicana, vol. XXXIII, núm. 1, México: El Colegio de México

Comaroff, Jean and John (1991), Of Revelation and Revolution. Christianity, Colonialism, and Consciousness in South Africa, vol. 1, Chicago: University of Chicago Press.

Comisión de Historia del 450 Aniversario de la Diócesis de Morelia (1986), Arzobispado de Morelia, Michoacán, México.

De la Peña, Guillermo (2004), "El campo religioso, la diversidad regional y la identidad nacional en México", en Relaciones, vol. XXV, núm. 100, Otoño, Michoacán: El Colegio de Michoacán, pp. 23-71.

Díaz Patiño, Gabriela (2003), "El catolicismo social en la Arquidiócesis de Morelia, Michoacán (1897-1913)", en Tzintzun, revista de Estudios Históricos, núm. 38, julio-diciembre, Michoacán, México: Instituto de Investigaciones Históricas-Universidad Michoacana de San Nicolás de Hidalgo, pp. 97-134.

Escalona Victoria, José Luis (2001), "Pluralismo y mediaciones: imaginario sociopolítico en Chiapas", en Salvador Maldonado Aranda (editor) Dilemas del estado nacional: una visión desde la cultura y el espacio regional, México: El Colegio de Michoacán-CIESAS.

Estrada Saavedra, Marco (2007), La comunidad armada rebelde y el EZLN. Un estudio histórico y sociológico sobre las bases de apoyo zapatistas en las cañadas tojolabales de la Selva Lacandona (1930-2005), México: El Colegio de México.

Guerra Manzo, Enrique (2008), "The Resistance of the Marginalised: Catholics in Eastern Michoacán and the Mexican State, 1920-1940", en J. Lat. Amer. Stud. 40, Cambridge: Cambridge University Press, pp.109-133.

Harvey, Neil (2000), La rebelión de Chiapas. La lucha por la tierra y la democracia, México: Ediciones Era.

Jasso Martínez, Ivy Jacaranda (2008), "Los movimientos indígenas, un marco para el análisis de las construcciones identitarias. Los casos de Organización Nación Purhépecha (Michoacán) y Servicios del Pueblo Mixe (Oaxaca)", Tesis de Doctorado, Michoacán, México: Centro de Estudios Rurales, El Colegio de Michoacán.
Joseph, Gilbert M. y Daniel Nugent (compiladores) (2002), Aspectos cotidianos de la formación del estado. La revolución y la negociación del mando en el México moderno, México: Ediciones Era.

Kirsch, Stuart (2007), "Indigenous movements and the risks of counterglobalization: Tracking the campaign against Papua New Guinea's", en American Ethnologist, vol. 34 , núm. 2.

Kuper, Adam (2003), "The Return of the Native", en Current Anthropology, vol. 44, núm. 3, June.

Lameiras Olvera, José (1999), "Una identidad mexicana decimonónica en la literatura novelística”, en José Eduardo Zárate (editor), Bajo el signo del Estado, Michoacán, México: El Colegio de Michoacán.

Máximo Cortés, Raúl (2003), "Orígenes y proyecto de Nación Purhépecha”, en Carlos Paredes Martínez y Marta Terán (Coordinadores), Autoridad y gobierno indígena en Michoacán, vol. II, Michoacán, México: El Colegio de Michoacán, INAH, CIESAS, UMSNH.

Meyer, Jean (1973), La cristiada, vol. 2, México: Siglo Veintiuno Editores.

Morales Bermúdez, Jesús (2005), Entre ásperos caminos llanos. La diócesis de San Cristóbal de Las Casas, 1950-1995, México: Casa Juan Pablos, Universidad de Ciencias y Artes de Chiapas, Universidad Intercultural de Chiapas, Consejo de Ciencia y Tecnología del Estado de Chiapas.

Muro, Víctor Gabriel (1994), Iglesia y movimientos sociales en México, 1972-1987. Los casos de Ciudad Juárez y el Istmo de Tehuantepec, México: Red Nacional de Investigación Urbana-El Colegio de Michoacán.

Plancarte, Roberto (1993), Historia de la Iglesia católica en México, México: F.C.E.-El Colegio Mexiquense.

Ramírez Sevilla, Luis (2002), "Propuesta de Ley sobre Derechos de los pueblos originarios del estado de Michoacán de Ocampo, (presentación)”, en Relaciones, vol. XXIII, núm. 90, Primavera, El Colegio de Michoacán, pp. 161-199.

Vázquez León, Luis (1992a), "Etnia y poder en Michoacán”, en Jesús Tapia Santamaría, Intermediación 
social y procesos políticos en Michoacán, Zamora, Michoacán, México: El Colegio de Michoacán.

Vázquez León, Luis (1992b), Ser indio otra vez. La purepechización de los tarascos serrano, Colección Regiones, México: CONACULTA.

Villoro, Luis (2002), Estado plural, pluralidad de culturas, México: Paidós-UNAM, (1998) segunda reimpresión. Weber, Max (1981), Economía y sociedad. Esbozo de sociología comprensiva, México: Fondo de Cultura Económica.

Weber, Max (2006), Estructuras de poder, México: Ediciones Coyoacán.
Zárate, José Eduardo (1999), "La reconstrucción de la Nación Purhépecha y el proceso de autonomía en Michoacán, México", en Willem Assies, Gemma van der Haar y Andrés Hoekema (Editores). El reto de la diversidad. Pueblos indígenas y reforma del Estado en América Latina, Zamora, Michoacán, México: El Colegio de Michoacán.

Zárate, José Eduardo (2001), Los señores de utopía. Etnicidad política en una comunidad p'urhépecha: Santa Fe de la LagunaUeamuo, México: El Colegio de Michoacán-CIESAS, segunda edición.

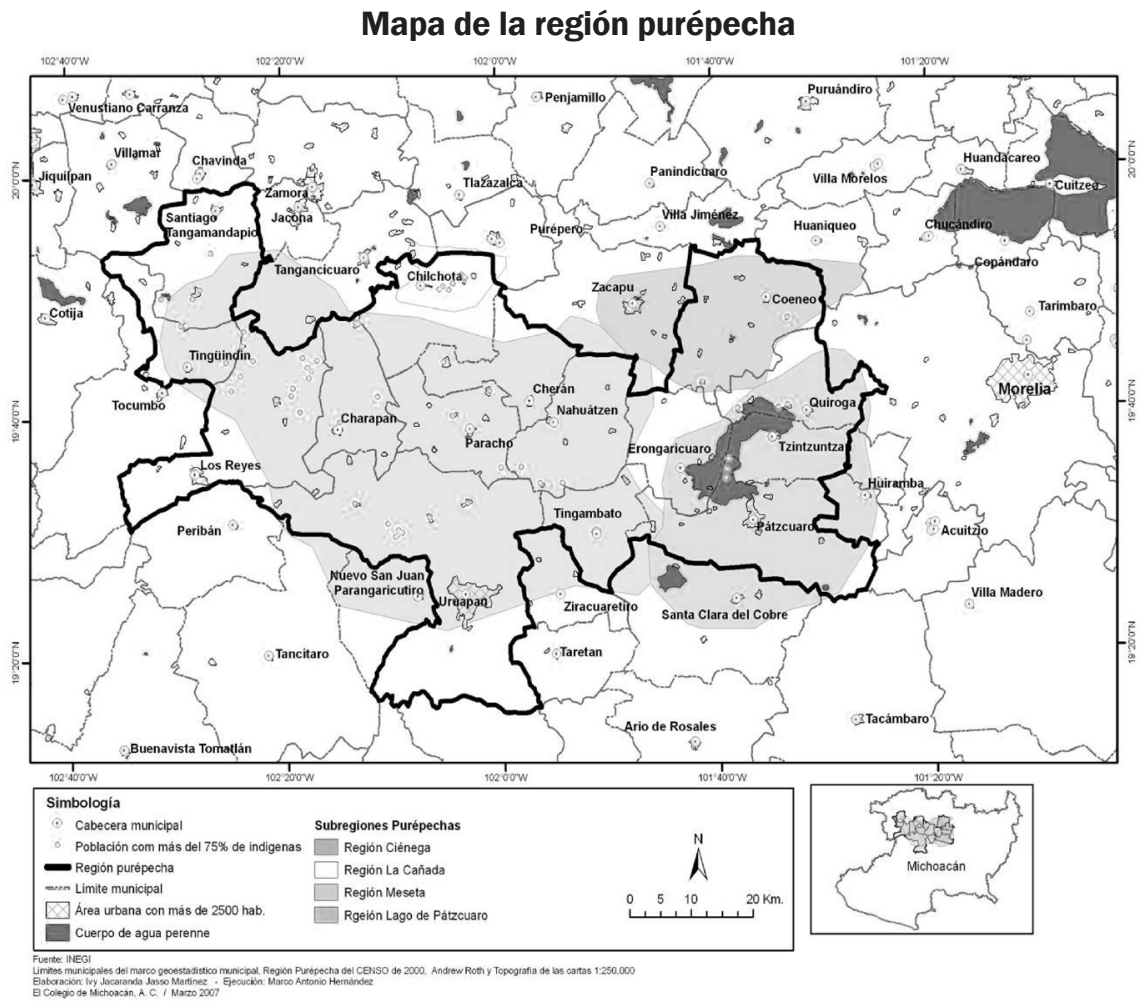

Tomado de Ivy J. Jasso (2008). En el mapa se ilustran las subregiones en que tiene influencia el actual movimiento indígena. Nótese que en las denominadas Región Ciénega, Lago de Pátzcuaro y en parte de la Meseta, fue donde los religiosos impulsaron la pastoral indianista de las décadas de 1940 y 1950. 